\title{
Developmental expression of mucin genes in the human gastrointestinal system
}

\author{
C J Reid, A Harris
}

\begin{abstract}
Background and aims-Mucin glycoproteins play a key role in the normal function of the epithelium lining the gastrointestinal tract. The expression of mucin genes, $M U C$ $3,4,5 A C, 5 B, 6,7$, and 8 in human fetal tissues was examined to establish the localisation and age of onset of expression of each mucin gene during human development. Methods-Mucin gene expression was assayed by mRNA in situ hybridisation.

Results-Expression of MUC3 was detected in the small intestine and colon from 13 weeks gestation onwards and at low levels in the main pancreatic duct at 13 weeks only. MUC4 expression was seen at a low level in the colonic epithelium from 13 weeks of gestation but not elsewhere in the gastrointestinal tract. MUC5AC mRNA was detected in the colon at 17 weeks and at high levels in the stomach at 23 weeks. MUC6 transcripts were evident in the pancreatic ducts from 13 weeks of gestation and at high levels in the stomach at 23 weeks. MUC5B, MUC7, and $M U C 8$ transcripts were not detected. Conclusions-Mucin genes are expressed from the early mid-trimester of gestation in the developing human fetal gastrointestinal tract.
\end{abstract}

(Gut 1998;42:220-226)

Keywords: mucin; developmental expression; gastrointestinal tract

Mucins (mucous glycoproteins) play a key role in the gastrointestinal system where their functions include lubrication and protection of epithelia from the oesophagus through to the colon and also in many accessory organs such as the pancreas and gall bladder. Mucins play a significant role in the pathology of many disorders of the digestive system including cancer and cystic fibrosis. There is one common feature of almost all mucin genes, which has come to be considered a motif for mucin, the tandem repeat. Mucin tandem repeats are regions of primary sequence (nucleic acid and amino acid) that contain several tandemly arrayed identical (or highly similar) repeats of shorter sequence elements. Mucin tandem repeat amino acid sequences generally contain a high percentage of serine and threonine residues that are the predominant sites of O-linked glycosylation.

Nine mucin genes have been identified, MUC 1, 2, 3, 4, 5AC, 5B, 6, 7, and $8,{ }^{1-12}$ although only MUC 1, 2, and 7 have been fully cloned. Partial sequence, generally from the tandem repeat, is available for the remainder of the genes. MUC1 and MUC7 are not classical gelforming mucins, and furthermore MUC1 is apparently unique in having a transmembrane anchor. MUC2 and MUC5AC are thought to be gel-forming mucins. ${ }^{13}$ The precise functions of MUC3, 4, and 6 are unclear. Studies of tissue localisation have been carried out for a number of mucins using antibodies; however, these studies have the limitation that many of the antibodies bind to carbohydrate determinants that are present on different mucin core proteins. Some protein epitopes may also be masked by glycosylation. Hence cell specific localisation of mucin gene expression is most reliably determined by using in situ mRNA hybridization with gene specific oligonucleotides or riboprobes.

We have previously examined the developmental expression of MUC1 and MUC2 mucins in the human gastrointestinal system. ${ }^{14}$ By 18 weeks MUC1 mRNA was detected in the colon while MUC2 mRNA was seen by 12 weeks gestation in the jejunum, ileum, and colon. We have now investigated the developmental expression of MUC3, MUC4, MUC5AC, MUC5B, MUC6, MUC7, and $M U C 8$ in human fetal gastrointestinal tract tissues by mRNA in situ hybridisation. MUC3 was expressed at high levels in the small intestine and colon from 13 weeks gestation through to term and in the epithelium of the main pancreatic duct at 13 weeks. MUC4 was expressed at low levels in the colonic epithelium at 13 weeks and at decreasing levels through to term. $M U C 5 A C$ transcripts were detected in the stomach at high levels by 23 weeks. MUC6 mRNA was expressed at low levels in the small intestine from 13 weeks through to 23 weeks, at high levels in the pancreatic ducts from 13 weeks gestation and also in the stomach by 23 weeks. MUC7 and MUC8 were not expressed in the developing gastrointestinal tract.

\section{Materials and methods}

Tissues from mid-trimester terminations were obtained with local ethical committee approval, and age was determined on the basis of foot length. Data presented here are derived from two 13 week fetuses (one male and one female), two 17/18 week fetuses (one male and one female) and one female fetus of 23 weeks gestation. Adult colon and small intestine epithelium was normal tissue adjacent to tumours removed at surgery. Tissues for in situ hybridisation were fixed directly in $4 \%$ paraformaldehyde $(\mathrm{pH} 9.5)$ overnight at $4^{\circ} \mathrm{C}$, embedded and frozen in liquid nitrogen before $10 \mu \mathrm{m}$ sections were cut. Frozen sections were
Accepted for publication 24 June 1997 
mounted on to Vectabond treated slides (Vector Laboratories Ltd) and stored desiccated at $-20^{\circ} \mathrm{C}$ until used.

IN SITU HYBRIDISATION

In situ hybridisation was carried out as described previously. ${ }^{14}$ The following $74 \mathrm{bp}$ double stranded oligonucleotide probes were used:

MUC3: GACCACATACCACAGTACTCCCAGCTTCACTTCTTTGATCACCATCACTGAGACC ACCTCACACAGTACTCCCA (bases 140-213; EMBL accession number M55405).

MUC4: CACAAGTCACGCCACCTCTCTTCTTGTCACCGACGCTTCCTCAGTATCCACAGGT GACACCACCCCTCTT-
CCTG (bases 111-184; EMBL accession number M64594)

$M U C 5 A C$ : CCCACGACCAGCACAACCTCTGCCCCTACAACAAGAACAACTTCTGCTCCTAAAA GCAGCACAACCTCTGCCGC (bases 58-131; EMBL accession number Z34278).

MUC5B: GGACGACCTGGATCCTCACAGAGCTGACCACAACAGACCACTACGACTGCATCC ACTGGATCCACGGCCACCCC (bases 221-294; EMBL accession number X74955).

MUC6: GGTCCACACACACAGCCCCACCAGTGACGCCGACCACCAGT-GGGACGAGCCAAG CCGCGAGCTCATTCAGCACA (bases 308-381; EMBL accession number L07517).
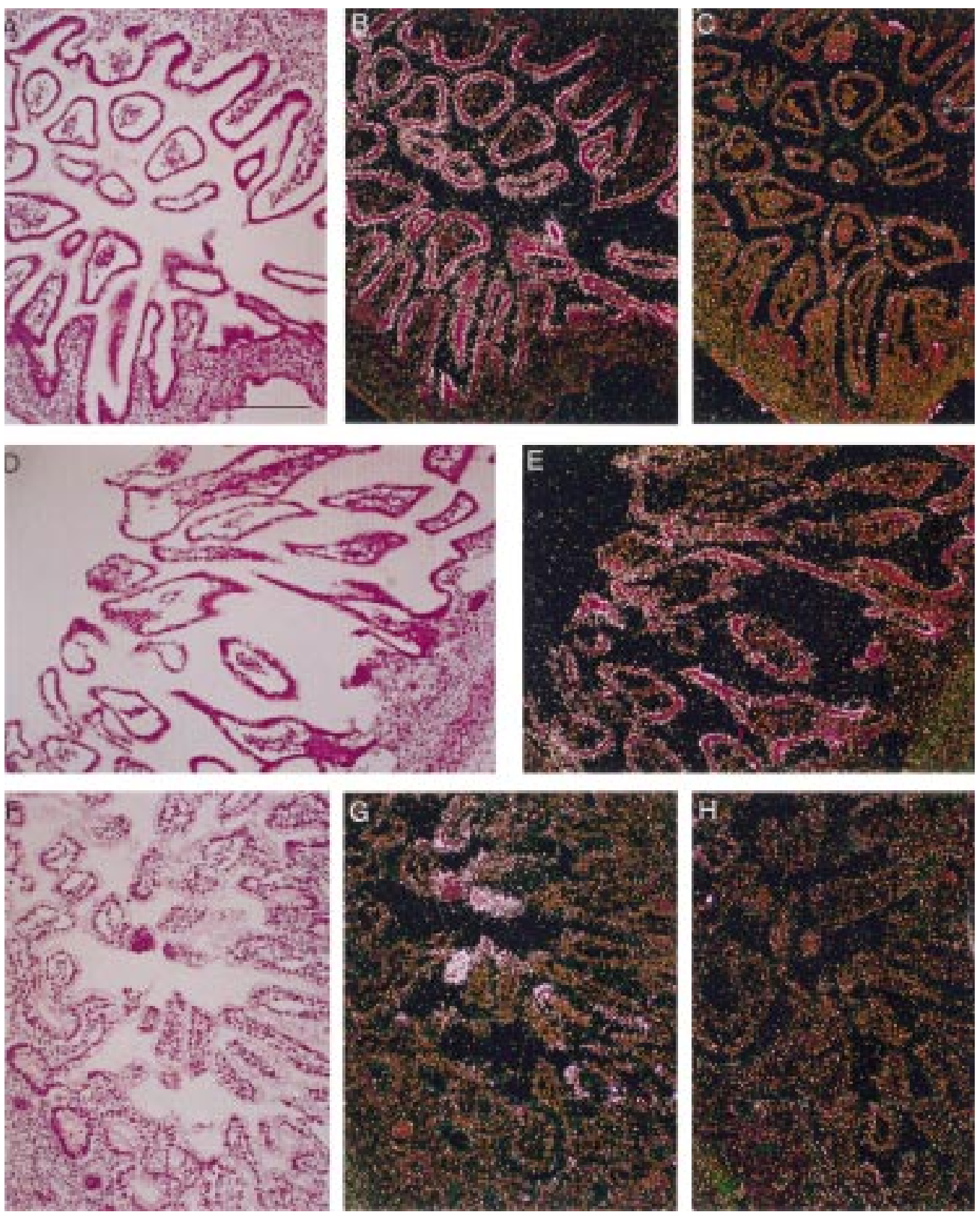

Figure 1 Expression of MUC3 mRNA in $13(A-C)$ and 17 (D and E) week small intestine and 17 week colon $(F-H)$. $A, D$, and $F$ show brightfield views of sections hybridised with the MUC3 antisense probe, and $B, E$, and $G$ show darkfield images of the sections shown in $A, D$, and $F$ respectively. $C$ and $H$ show darkfield views of sections consecutive to those shown in $A$ and $F$ hybridised with the MUC3 sense negative control probe, and equivalent results were seen with the MUC3 sense negative control for the 17 week small intestine shown in $D$ and $E$ (not shown). The size bar shown in $A$ corresponds to $200 \mu \mathrm{m}$ in $A-C$ and $F-H$ and $100 \mu m$ in $D$ and $E$. 
MUC7: ACACCACAGCTGCCCCACCCACACCTTCTGCAACTACACCAGCTCCACCATCTTC CTCAGCTCCACCAGAGACC (bases 587-660; EMBL accession number L13283).

MUC8: CCGGGTTCATGAGCTGCCCACGCCCTTTCCAGGAAGGGACCCCGGGTTCACGAGC TGCCCACGTCCTCTCCAGG (bases 35-109; EMBL accession number U14383).

Each oligonucleotide carried additional bases to enable direct cloning into the BamHI and HindIII sites of pBluescript SK. Antisense and sense probes were generated from the $\mathrm{T} 7$ and T3 promoters respectively. An additional probe for MUC8 mRNA (pAM3-3) which includes bases $1-312$ of the pAM 1 clone $^{12}$ that encompasses part of the MUC8 tandem repeat was kindly provided by Dr G Sachdev. Purified probes were diluted to $5 \times 10^{6}-2 \times 10^{7}$ $\mathrm{cpm} / \mathrm{ml}$ in a hybridisation solution containing formamide (final concentration 60-65\%), $1 \times$ Denhardt's solution, $10 \%$ dextran sulphate, $0.5 \mathrm{mg} / \mathrm{ml} \mathrm{RNase-free} \mathrm{tRNA} \mathrm{and} 10 \mathrm{mM}$ dithiothreitol.

Tissue sections were digested with $10 \mu \mathrm{g} / \mathrm{ml}$ proteinase $\mathrm{K}$ for $2 \mathrm{~min}$ at $37^{\circ} \mathrm{C}$, then treated with $25 \mathrm{mM}$ acetic anhydride in $0.1 \mathrm{M}$ triethanolamine $(\mathrm{pH} 8.0)$ for $10 \mathrm{~min}$ at room temperature; they were then briefly rinsed in 2 $\times$ SSC (where $1 \times$ SSC is $0.15 \mathrm{M} \mathrm{NaCl} / 0.015$ $\mathrm{M}$ sodium citrate) before dehydration through a graded ethanol series and air dried. As a control for non-specific binding of the antisense probe, some sections were treated with $20 \mu \mathrm{g} / \mathrm{ml}$ RNase A for $15 \mathrm{~min}$ at room temperature before incubation with proteinase K.

Hybridisation was carried out overnight at $55-60^{\circ} \mathrm{C}$. After hybridisation, slides were washed four times in $4 \times$ SSC at room temperature and digested with RNase A for 30 min at $37^{\circ} \mathrm{C}$. Sections were washed at a final stringency of $0.1 \times \mathrm{SSC}$ at $60^{\circ} \mathrm{C}$ or $70^{\circ} \mathrm{C}$ for 30 min and dehydrated. Slides were exposed to Kodak Nuclear Tracking (NTB-2) liquid emulsion for $10-14$ days at $4^{\circ} \mathrm{C}$. The slides were developed, fixed, and counterstained with haematoxylin and eosin.

\section{Results}

Mucin gene expression was analysed at 13 weeks, 17/18 weeks, and 23 weeks of gestation and in adult colon and small intestine. Data presented here are from two fetuses at 13 weeks, two at $17 / 18$ weeks, and one at 23 weeks. Other fetuses of the same ages have been examined for mucin gene expression and there was no significant variation in the patterns between different fetuses of the same gestational age.

\section{MUC3}

Abundant MUC3 mRNA was expressed in most cells in the villus epithelium of the small intestine, although not in the crypts. MUC3 transcripts were also detected at lower levels in epithelial cells at the tips of colonic villi from 13 weeks of gestation through to term. In fig 1, expression of MUC3 mRNA is shown
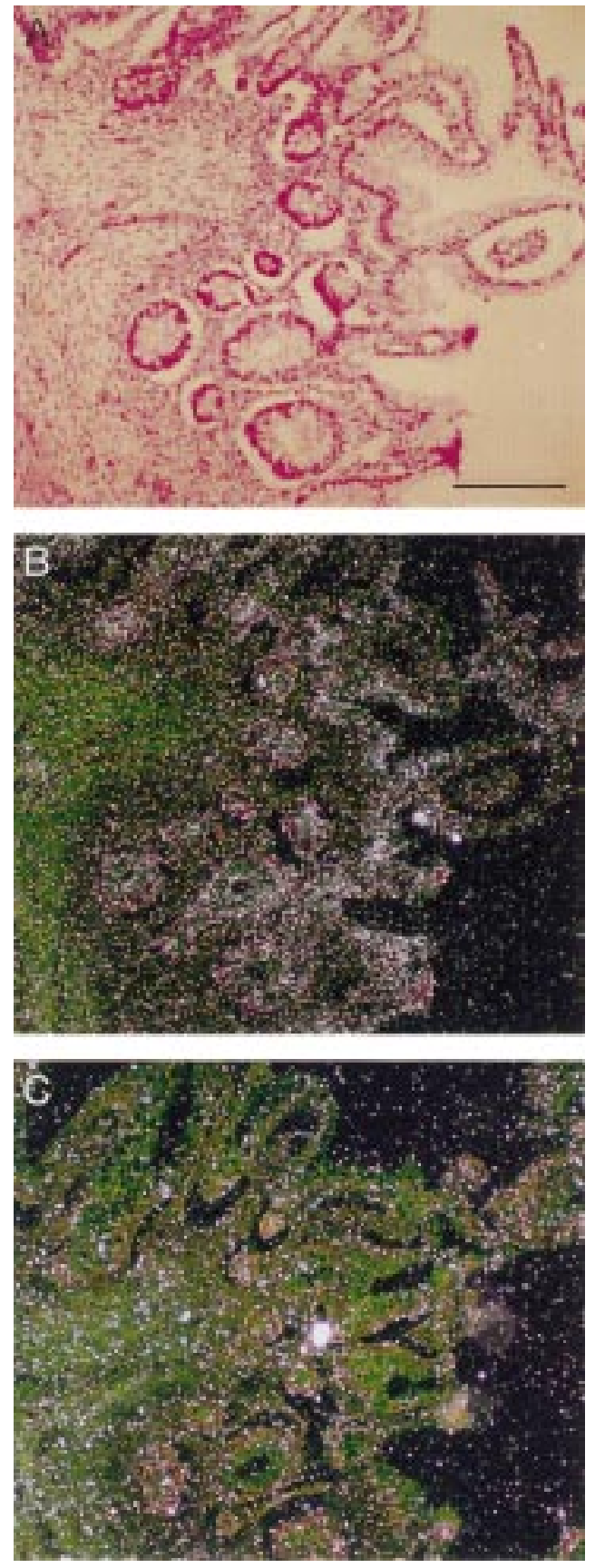

Figure 2 Expression of MUC5AC mRNA in 17 week fetal colon. A shows a brightfield view of a section hybridized with the MUC5AC antisense probe and B shows a darkfield image of the same section. $C$ shows a darkfield view of a consecutive section hybridised with the MUC5AC sense negative control probe. The size bar shown in $A$ corresponds to $200 \mu \mathrm{m}$ for all panels.

in 13 week (panels $\mathrm{A}-\mathrm{C}$ ) and 17 week (panels $\mathrm{D}$ and $\mathrm{E}$ ) small intestine and 17 week colon (panels $\mathrm{F}-\mathrm{H}$ ). In adult intestine (not shown), abundant MUC3 transcripts were seen in most cells in the villus epithelium of the small intestine with substantially lower levels in colonic epithelium. MUC3 transcripts were seen in most epithelial cells lining the main pancreatic duct at 13 weeks, although not later in gestation. No MUC3 mRNA was detected elsewhere in the pancreas at any gestational age or in the stomach. 

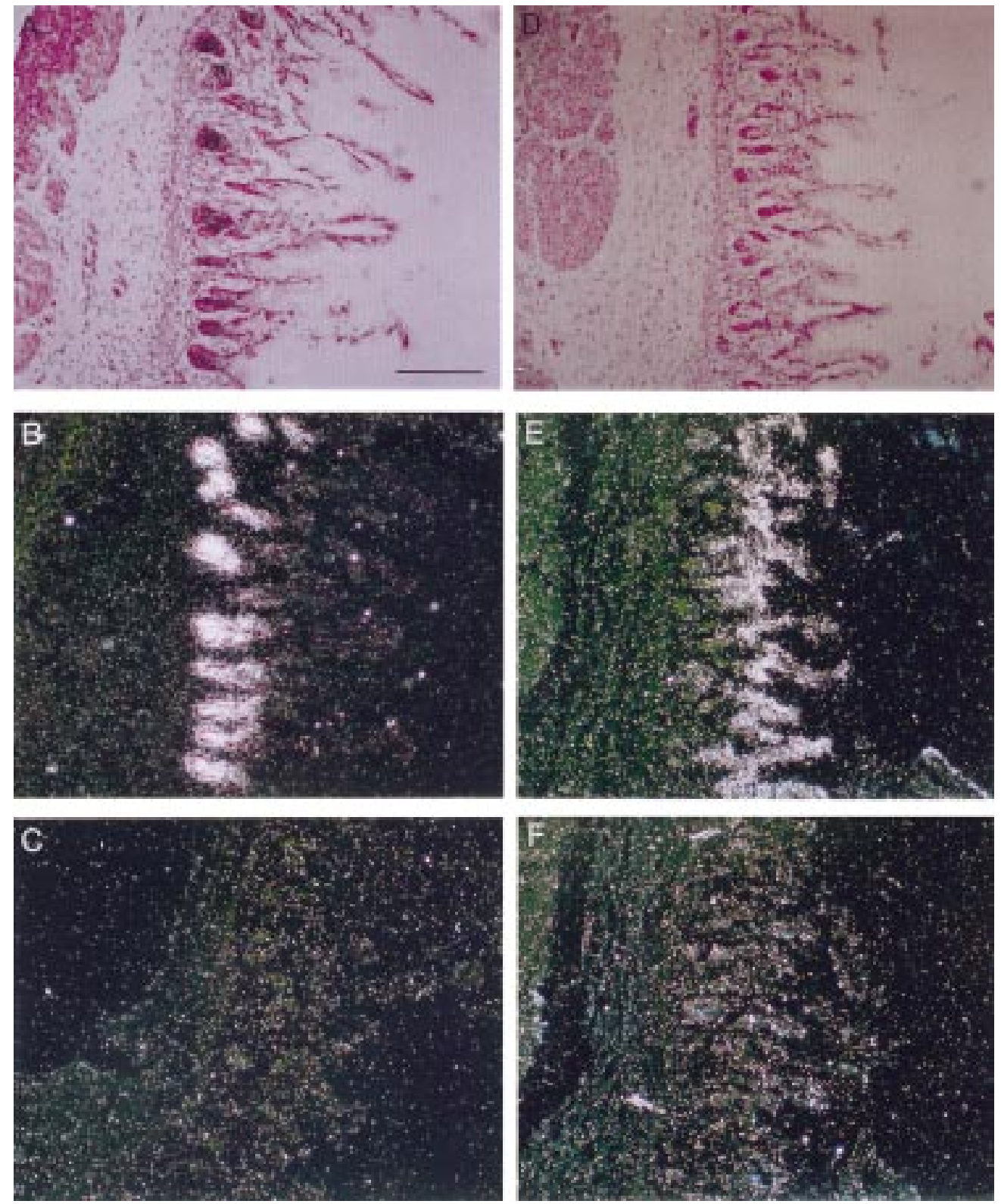

Figure 3 Expression of MUC5AC (D-F) and MUC6 $(A-C) m R N A$ in 23 week stomach. D and $A$ show a brightfield view of a section hybridised with the MUC5AC and MUC6 antisense probes respectively and $E$ and $B$ show darkfield images of the same respective sections. $F$ and $C$ show darkfield views of consecutive sections hybridised with the MUC5AC and MUC6 sense negative control probes respectively. The silver grains generated by probe hybridisation to the MUC6 $m R N A$ appear as black dots in the bright field pictures and white dots in the dark field view. The size bar shown in $A$ corresponds to $200 \mu \mathrm{m}$ for all panels.

MUC4

MUC4 transcripts were detected at low and decreasing levels in the colonic epithelium from 13 weeks through to 23 weeks of gestation (data not shown). MUC4 mRNA was not detected in the small intestine, pancreas, or stomach at any gestational age, nor was it seen in adult ileum or colon.

\section{MUC5AC}

Low levels of MUC5AC expression were detected in the colonic epithelium at 17 weeks of gestation (fig 2) but MUC5AC transcripts were not seen elsewhere in the small intestine or colon during the mid-trimester nor were they detected in the pancreas.

In the stomach, high levels of MUC5AC mRNA were observed at 23 weeks gestation in the surface mucous cells of the epithelium, but $M U C 5 A C$ transcripts were absent from neck mucous cells (fig $3 \mathrm{D}-\mathrm{F}$ ). MUC5AC transcripts were not detected in adult ileum or colon.

\section{$M U C 5 B$}

No $M U C 5 B$ expression was detected in any part of the gastrointestinal tract during gestation, although the MUC5B probe was effective at detecting MUC5B mRNA in adult colon (not shown) and has been shown to detect MUC5B mRNA in airway submucosal glands. ${ }^{19}$

\section{MUC6}

MUC6 transcripts were detected at very low levels in the small intestine from 13 weeks of gestation onwards (data not shown) and at high 
levels in the neck mucous cells of the stomach at 23 weeks (fig $3 \mathrm{~A}-\mathrm{C}$ ). No MUC6 mRNA was detected in the surface mucous cells of the stomach epithelium in contrast with MUC5AC mRNA. MUC6 mRNA was not present in the colon at any gestational age examined.

In the pancreas MUC6 mRNA was expressed at high levels from 13 weeks onwards in the epithelium of small ducts and in developing acini (fig 4). Later in gestation the distribution of MUC6 transcripts followed the developing pancreatic ducts with expression in the epithelium of small ducts, centroacinar cells, and acini (data not shown). MUC6 transcripts were absent from the epithelium of adult ileum and colon.
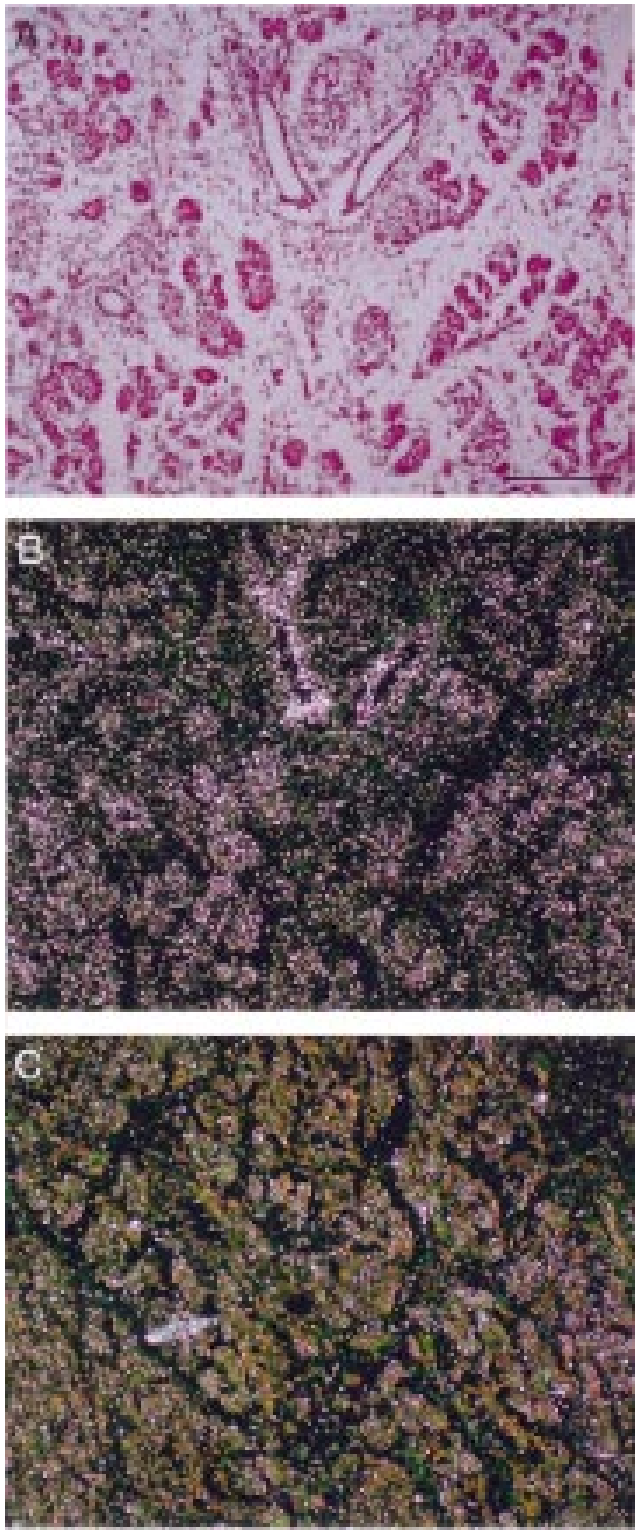

Figure 4 Expression of MUC6 mRNA in 13 week fetal pancreas. A shows a brightfield view of a pancreas section hybridised with the MUC6 antisense probe, and B shows a darkfield image of the same section. $C$ shows a darkfield view of a consecutive section hybridised with the MUC6 sense negative control probe. The size bar shown in $A$ corresponds to $200 \mu \mathrm{m}$ for all panels.
Table 1 Developmental expression of mucins in human gastrointestinal tissue

\begin{tabular}{|c|c|c|c|c|}
\hline Organ & $\begin{array}{l}13 \text { week } \\
\text { old fetus }\end{array}$ & $\begin{array}{l}17 \text { week } \\
\text { old fetus }\end{array}$ & $\begin{array}{l}23 \text { week } \\
\text { old fetus }\end{array}$ & Adult \\
\hline \multicolumn{5}{|l|}{ Small intestine } \\
\hline MUC3 & +++ & +++ & +++ & +++ \\
\hline MUC4 & - & - & - & - \\
\hline MUC5AC & - & - & - & - \\
\hline MUC5B & - & - & - & - \\
\hline MUC6 & $+/-$ & $+/-$ & $+/-$ & - \\
\hline MUC7 & - & - & - & - \\
\hline MUC8 & - & - & - & - \\
\hline \multicolumn{5}{|l|}{ Colon } \\
\hline MUC3 & +++ & +++ & +++ & + \\
\hline MUC4 & ++ & + & $+/-$ & - \\
\hline MUC5AC & - & + & - & - \\
\hline MUC5B & - & - & - & $+/-$ \\
\hline MUC6 & - & - & - & - \\
\hline MUC7 & - & - & - & - \\
\hline MUC8 & - & - & - & - \\
\hline \multicolumn{5}{|l|}{ Pancreas } \\
\hline MUC3 & $+/-$ & - & - & \\
\hline MUC4 & - & - & - & \\
\hline MUC5AC & - & - & - & \\
\hline MUC5B & - & - & - & \\
\hline MUC6 & +++ & +++ & +++ & \\
\hline MUC7 & - & - & - & \\
\hline MUC8 & - & - & - & \\
\hline \multicolumn{5}{|l|}{ Stomach } \\
\hline MUC3 & & & - & \\
\hline MUC4 & & & - & \\
\hline MUC5AC & & & +++ & \\
\hline MUC5B & & & - & \\
\hline MUC6 & & & +++ & \\
\hline MUC7 & & & - & \\
\hline MUC8 & & & - & \\
\hline
\end{tabular}

MUC3, MUC4, and MUC5AC are expressed in most epithelia cells in the tissues where transcripts were found. In the stomach MUC5AC mRNA is found in surface mucous cells and MUC6 mRNA in the neck mucous cells. Stomach tissue was not available from 13 and 17 week old fetuses.

$M U C 7$ AND $M U C 8$

MUC7 and MUC8 transcripts were not detected in any parts of the developing gastrointestinal tract that we have examined at any gestational age. The MUC7 probe was shown to be effective at detecting MUC7 mRNA in airway submucosal glands. ${ }^{19}$ However, owing to the failure to detect $M U C 8$ transcripts in adult lung with two probes for MUC8, ${ }^{19}$ we are uncertain whether the level of expression of this mucin in any epithelial cells is too low to be detected by the in situ hybridisation technique.

All negative data for MUC3-MUC6 reported above are genuine observations as $(a)$ positive results were obtained from the same tissues on adjacent sections hybridised with other probes and $(b)$ all probes gave positive results on some of the tissues examined. ${ }^{19}$

Table 1 gives a summary of the developmental expression of mucins in human gastrointestinal tissue.

\section{Discussion}

The developmental expression of mucin genes is of importance in the context of neonatal diseases of the digestive system. We have previously examined the expression of $M U C 1$ and MUC2 in human development. ${ }^{14}$ MUC1 expression commenced relatively late in gestation, at 16 weeks in the colonic crypts and in the third trimester in large interlobular pancreatic ducts where it was seen in most of the cells in the epithelium. MUC2 expression was detected at high levels from 12 weeks of gestation but was restricted to goblet cells in the jejunum, ileum, and colon. 
We have now shown that in addition to MUC2, MUC3 is expressed from 13 weeks of gestation in the epithelium of the small intestine, although the cell-specific pattern of expression of the two genes is different. MUC2 transcripts were restricted to goblet cells in the crypt and villus epithelium. MUC3 transcripts were detected in most cells in the villus epithelium but were not seen in the crypts. MUC3 transcripts were also seen in the colon from 13 weeks of gestation but were restricted to the tips of the colonic villi. MUC4 expression was seen at low levels throughout the colonic epithelium from 13 weeks of gestation onwards, with decreasing levels through to term. Low levels of MUC6 mRNA were seen in the small intestine but not in the colon from 13 weeks gestation through to 23 weeks.

MUC3 expression in the epithelium of the main pancreatic duct was restricted to low levels at 13 weeks of gestation, although MUC6 transcripts were detected from 13 weeks onwards throughout the pancreatic duct system in small interlobular and intralobular ducts and in developing acini.

In the stomach, high levels of MUC5AC and MUC6 mRNA were seen at 23 weeks, although the two genes had distinct cellular expression patterns. MUC5AC expression was restricted to surface mucous cells while MUC6 expression was seen only in neck mucous cells. This differential distribution is likely to reflect the functional differences in these two parts of the epithelium.

Our data show some differences between expression of intestinal mucins in utero and patterns of expression in adult ileum and colon-for example, the expression of MUC4 mRNA in colonic epithelium during the mid-trimester but not in adult colon and the transient expression of MUC5AC in goblet cells in 17 week colon. However, in general the patterns of expression of MUC3-MUC8 in mid-trimester human fetal tissues correspond to those seen in this study and by others ${ }^{15-17}$ in adult tissues. Differences between published studies of adult mucin gene expression can largely be accounted for by the use of in situ hybridisation or immunocytochemistry as a detection method, with the potential of the latter for false positive results because of antibody cross reactivity.

The involvement of mucins in the pathology of cystic fibrosis is well established and hence it is relevant to compare the developmental expression of the cystic fibrosis transmembrane conductance regulator gene (CFTR) with the expression patterns of the different mucin genes during human gestation. The aim of this comparison is to establish which mucins may be involved in the pathological changes that occur in different organs in cystic fibrosis in utero. We have previously examined the expression of CFTR during human development. ${ }^{18}$ In the small intestine and colon, CFTR mRNA is detected from 12 weeks of gestation through to term but is restricted to the crypt epithelium and a few isolated cells of unknown function within the villous epithelium. This is in contrast with
MUC2 and MUC3 transcripts, which, although they are present in abundance at the same developmental age, are in the case of MUC2 restricted to goblet cells in the crypt and villous epithelium, while MUC3 is expressed throughout the villous epithelium. MUC4 and MUC5AC mRNAs when they are detected in the fetal intestine do not specifically localise to the cells that express CFTR. These data provide additional evidence to support the hypothesis that mucin abnormalities in cystic fibrosis arise as the result of extracellular events caused by the lack of expression of a functional CFTR cAMP-activated chloride ion channel within the intestinal epithelium.

It is of interest in the context of cystic fibrosis, where $15 \%$ of babies are born with the complication of meconium ileus, and in other bowel obstruction syndromes of the perinatal period, that several mucin genes including MUC2, MUC3, MUC4, and MUC6 are transcribed from the start of the mid-trimester of gestation, and possibly even earlier. This provides ample time during fetal development for mucin related problems to develop. The observations in the intestine are in contrast with the developmental expression of mucins in the lung, where few mucin genes are transcribed until relatively late in gestation. ${ }^{19}$ This may in part account for the severe intestinal disease that often accompanies cystic fibrosis at birth in the absence of substantial lung pathology.

We are grateful to Simon Biddolph, Zahra Madgwick, and Drs $\mathrm{P}$ Tam and B Warren for their assistance, also to Professor R Moxon for his support. This work was supported by the Cystic Fibrosis Research Trust, UK and grant DK46589 from the Fibrosis Research Trust, UK
National Institutes of Health

1 Porchet N, Van Cong N, Dufosse J, et al. Molecular cloning and chromosomal localization of a novel human tracheobronchial mucin cDNA containing tandemly repeated sequences of 48 base pairs. Biochem Biophys Res Commun 1991;175:414-22.

2 Crepin M, Porchet N, Aubert JP, Degand P. Diversity of the peptide moiety of human airway mucins. Biorheology 1991; 27:471-84.

3 Dufosse J, Porchet N, Audie JP, et al. Bioche. $f$ 1993;293: 329-37.

4 Gendler SJ, Lancaster CA, Taylor-Papadimitriou J, et al. Molecular cloning and expression of the human tumourassociated polymorphic epithelial mucin, PEM. F Biol Chem 1990;265:15286-93.

5 Lan MS, Batra SK, Qi WN, et al. Cloning and sequencing of a human pancreatic tumor cDNA. F Biol Chem 1990;265: 15294-9.

6 Gum JR, Byrd JC, Hicks JW, et al. Molecular cloning of human intestinal mucin cDNAs. F Biol Chem 1989;264: 6480-7.

7 Gum JR, Hicks JW, Toribara NW, et al. The human MUC2 intestinal mucin has cysteine-rich subdomains located both upstream and downstream of its central repetitive region. $\mathcal{F}$ Biol Chem 1992;267:21375-83.

8 Jany BH, Gallup MW, Yan P-S, et al. Human bronchus and intestine express the same mucin gene. F Clin Invest 1991; 87:77-82.

9 Gum JR, Hicks JW, Swallow DM, et al. Molecular cloning of cDNAs derived from a novel human intestinal mucin gene. Biochem Biophys Res Commun 1990;171: 407-15.

10 Toribara NW, Robertson AM, Ho S, et al. Human gastric mucin. F Biol Chem 1993;268:5879-85.

11 Bobek LA, Tsai H, Biesbrock AR, Levine MJ. Molecular cloning, sequence, and specificity of expression of the gene encoding the low molecular weight human salivary mucin (MUC7). F Biol Chem 1993;268:20563-9.

12 Shankar V, Gilmore MS, Elkins RC, Sachdev GP. A novel human airway mucin cDNA encodes a protein with unique tandem repeat organization. Biochem $\mathcal{f} 1994$; 300:295-8.

13 Kim YS, Gum JR. Diversity of mucin genes, structure, function and expression. Gastroenterology. 1995;109:9991013. 
14 Chambers JA, Hollingsworth MA, Trezise AEO, Harris A Developmental expression of mucin genes MUC1 and Developmental expression of mucin

15 Chang SK, Dohrman AF, Basbaum CB, et al. Localization of mucin (MUC2 and MUC3) messenger RNA and peptide expression in human normal intestine and colon cancer. Gastroenterology 1994;107:28-36.

16 Audie JP, Janin A, Porchet N, et al. Expression of human mucin genes in the respiratory, digestive and reproductive tracts ascertained by in situ hybridization. $\mathcal{F}$ Histochem Cytochem 1993;41:1479-85.
17 Ho S, Robertson AM, Shekels LL, et al. Expression cloning of gastric mucin complementary cDNA and localization of mucin gene expression. Gastroenterology 1995;109:73547

18 Trezise AEO, Chambers JA, Wardle CJ, et al. Expression of the cystic fibrosis gene in human fetal tissues. Hum $\mathrm{Mol}$ Genet 1993; 2:213-18.

19 Reid CJ, Gould S, Harris A. Developmental expression of mucin genes in the human respiratory tract. Am $\mathcal{F}$ Respir Cell Mol Biol 1997;17:592-8.

\section{Gut-http://www.gutjnl.com}

Visitors to the world wide web can now access Gut either through the BMJ Publishing Group's home page (http://www.bmjpg.com) or directly by using its individual URL (http://www.gutjnl.com). There they will find the following:

- Current contents list for the journal

- Contents lists of previous issues

- Members of the editorial board

- Subscribers' information

- Instructions for authors

- Details of reprint services.

A hotlink gives access to:

- BMJ Publishing Group home page

- British Medical Association web site

- Online books catalogue

- BMJ Publishing Group books

The web site is at a preliminary stage and there are plans to develop it into a more sophisticated site. Suggestions from visitors about features they would like to see are welcomed. They can be left via the opening page of the BMJ Publishing Group site or, alternatively, via the journal page, through "about this site". 